\title{
Ser mulher cuidadora de pessoas com deficiência à luz da categoria gênero: reflexões a partir de um projeto de ensino/pesquisa/ extensão no campo da educação física
}

Being a woman carer for people with disabilities in the light of the category of gender: reflections of a project of teaching/research/extension in the field of physical education

\author{
Erineusa Maria da Silva \\ Universidade Federal do Espirito Santo, Brasil \\ erineusams@yahoo.com.br \\ Rafaela Bernardes \\ Universidade Federal do Espirito Santo, Brasil \\ rafa.o.bernardes@hotmail.om \\ José Francisco Chicon \\ Universidade Federal do Espirito Santo, Brasil \\ chiconjf@yahoo.com.br \\ Ivone Martins de Oliveira \\ Universidade Federal do Espirito Santo, Brasil \\ imartinsdeoliveira3@gmail.com \\ Maria das Graças Carvalho Silva de Sá \\ Universidade Federal do Espirito Santo, Brasil \\ mgracasilvasa@gmail.com
}

\section{Resumo:}

O estudo objetiva analisar o ser mulher, cuidadora de pessoas com deficiência, à luz da categoria gênero, a partir de um projeto de ensino/pesquisa/extensão no campo da Educação Física. Os sujeitos da pesquisa foram sete mães dos jovens e adultos com deficiência intelectual participantes do projeto de extensão "Cuidadoras que dançam". O trabalho de cunho qualitativo utilizou como instrumento para recolha de dados a entrevista semiestruturada com interpretações baseadas nas análises de conteúdo. Conclui que as mães cuidadoras estão nesse lugar por uma construção histórico-cultural e que há uma sobrecarga de trabalho imputada à figura feminina que carece do desenvolvimento de políticas públicas equitativas desse trabalho de cuidado entre o Estado e a família.

Palavras-chave: Mulher, Gênero, Família, Pessoa com deficiência, Educação Física.

\section{ABstraCT:}

This study aims to analyze the woman, caregiver of disabled people, according to gender category, from a project of teaching/ research/extension in the field of Physical Education. The subjects of research were seven mothers of young people and adults with intellectual disabilities who participate in the extension project "Caregivers who dance". This qualitative-nature work used as instrument for collecting data the semi-structured interview with interpretations based on content analysis. We concluded that mothers caregivers are in this place because of a cultural-historic construction and that there is an overload of work allocated to female figures who lack the development of equitable public policies for caring work between the State and the family.

KEYWORDS: Woman, Gender, Family, Person with disability, Physical education.

\section{INTRODUÇÃo}

A forte movimentação social internacional, em fins do século passado, no que tange os direitos das pessoas 
com deficiência ${ }^{1}$ engendrou o reordenamento legal que reverberou na promoção de documentos e tratados de caráter internacional. ${ }^{2}$ Esse reordenamento se direcionou a promoção de políticas públicas de caráter igualitário e inclusivo, especialmente no que tange a implementação de ações inclusivas destinadas aos sujeitos ou grupos que se encontram em situação de desvantagem social. Tais movimentos fundamentaram seus pressupostos na valorização da diversidade como ferramenta singular ao desenvolvimento humano, a emancipação e a equidade de oportunidades a todos/as (Scussiatto, 2015).

No Brasil, a recepção dessa declaração gerou um ordenamento próprio que provocou nos entes que desenvolvem políticas públicas uma reavaliação de seus pressupostos na direção de se pensar uma sociedade comprometida com uma formação humana que tome o direito à diversidade como uma premissa (Chicon; Sá, 2012). Nesse caminhar, o meio acadêmico se fortaleceu, ampliando as discussões a respeito do públicoalvo da Educação Especial e os processos inclusivos mediados pelos campos da saúde e educação. A Educação Física, nesse processo, teve que também repensar suas práticas a partir do entendimento de que deve criar meios de participação da pessoa com deficiência atuando contra possíveis obstáculos materiais e imateriais que atuam como impeditivos, como perspectivado por Venturiello \& Ferrante (2018).

Apesar dos avanços percebidos em relação ao trato com esse publico pelo campo da Educação Física, a discussão sobre a família da pessoa com deficiência ainda é pouco explorada pelo meio acadêmico, em especial no que tange à figura da pessoa que cuida de filhos $/ \mathrm{as}^{3}$ com deficiência - geralmente uma mulher.

Para Blascovi-Assis (1997), o nascimento do/a filho/a com deficiência causa diversas complicações provenientes de sentimentos de culpa, negação, rejeição e, em consequência, mudanças tanto na relação quanto na estrutura dessa família. Tais mudanças ocorrem principalmente na vida da mãe, que é quem na maioria das vezes assume, ou é chamada a assumir, o compromisso e a responsabilidade de cuidar deste filho/a (Oliveira \& Finelli, 2014), principalmente em uma sociedade que tarda em assumir o atendimento da pessoa com deficiência como um direito social. A mãe, segundo Barbosa, Chaud e Gomes (2007, p. 51):

[...] vê-se diante da necessidade de deixar o trabalho para atender às demandas de cuidado do filho deficiente [com deficiência], e também devido à dificuldade inicial em lidar com os sentimentos e conflitos vividos. Sente-se incapaz de levar uma vida como tivera antes da chegada do filho e, assim, lança-se às exigências impostas pela situação vivenciada na família e no cuidado dele [...].

A ideia de que é uma função da mulher o compromisso com o cuidado está assentada em resquícios de uma cultura patriarcal que, apesar dos progressos no campo das relações de gênero, teima em permanecer pelo que entendemos ser um habitus de gênero (Bourdieu, 2005; Mcnay, 1999; Silva, 2017) constituído ao longo de séculos. A ideia da constituição de um habitus de gênero se baseia na noção de habitus de Bourdieu (2005) como o princípio unificador e gerador de todas as práticas e, em particular, das orientações comumente descritas como "escolhas" da vocação.

Para Bourdieu (2005), o habitus é durável, pois expressa uma fé prática, ou seja, uma crença na veracidade das regras do campo no qual está imerso e isso inclinaria o agente a agir em conformidade a essas regras, mas o habitus não é imutável tendo em vista o volume e a estrutura do capital eficiente dentro do campo ao qual o agente se insere. Por sua vez, o campo é basicamente um espaço de jogo de estratégias no qual se estabelecem relações entre os participantes, chamados por ele de agentes. Essas relações estabelecidas são da ordem da luta, da ordem dos conflitos de interesse. Cada agente que participa desse jogo de estratégias o faz a partir de uma posição dentro desse campo e ali pode lutar, criar, recriar, não sendo sujeitos estáticos, já que, nesse campo, há uma margem de manobra.

O habitus é um conceito central na teoria do campo social de Bourdieu, pois nos ajuda a compreender como os agentes se movem dentro desse campo, ou seja, como o manobram. Habitus, então, é o elemento que vincula o mundo subjetivo ao mundo objetivo. Ele é um modo de ação e de pensar originado da posição do/da agente dentro do campo. Esse conceito abarca as margens de manobra, pois o/a agente aprende as regras da instituição, ou seja, o que é esperado dele/dela. O/A agente internaliza as pautas e regras específicas das instituições dadas pelas condições objetivas, não sendo mera peça estática do processo. Nesse sentido, nosso entendimento é que o/a agente aprende também a se movimentar em relação ao que dele/dela se espera 
também no sentido das relações de gênero que serão estabelecidas, quanto aos comportamentos, atitudes, enfim, modos de agir.

A incorporação de um habitus de gênero, como uma destacada dimensão do social, incide sobre a formação das mães, individual e coletivamente, informando suas ações de cuidado. $\mathrm{O}$ habitus de gênero, fruto de um conjunto de capitais diferenciados que se estruturam e reestruturam durante a vida, num processo de socialização longo, lento e difuso, é matriz de percepção que engendra as identidades de gênero e as ações das mães e contribui para a construção do habitus materno. Assim, dito de outra maneira, o ser e o agir das mães são marcados pelas posições sociais que elas ocupam no espaço social que é, por sua vez, marcado pela distinção entre gêneros.

Nessa acepção, percebemos que a sociedade ainda delega à mulher a responsabilidade do cuidado do/a filho/a, como se ela fosse a única que apresenta capacidade para realizar tal tarefa. Essa atribuição legitimada socialmente gera um sentimento de dever, de não se eximir de tal função. Se, para a mulher que tem filhos/ as que não apresentam deficiências, a maternidade já é bastante naturalizada como sinônimo de cuidado, para a que tem filha/o com alguma deficiência, pela própria situação de dificuldade com o cuidado, isso se potencializa. Nesse processo, apesar de as resistências produzidas pelas mães no sentido de tornar esse espaço de cuidado uma responsabilidade também de seus companheiros e do poder público, no geral, as mães tendem a abdicar da vida profissional que tinham anterior ao nascimento da/o filha/o. Essa situação de conflito constante provoca sentimentos negativos, como angústia e stress, podendo influenciar diretamente a possibilidade de um exercício de vida mais pleno.

Em que pesem os avanços na posição social da mulher, parcela das mulheres/mães deixam de viver a sua vida, de realizar os seus sonhos, de satisfazer os seus desejos para se dedicar, quase exclusivamente, ao cuidado do/a filho/a. Segundo Falkenbach, Drexsler e Werler (2008), essa mudança no cotidiano se dá pela necessidade constante de supervisão, de assistência e de cuidado para a/o filho/a, especialmente, com deficiência, pois tais atividades não são assumidos como direito social.

Pressupomos que essa situação percebida acerca da família da pessoa com deficiência, em especial da mãe, ocorre fundamentalmente pela posição de gênero assumida/imputada pela/na mulher na sociedade. Nesse sentido, pensamos ser importante compreender: a) as relações existentes entre as posições de sujeitos sociais tomadas pelas mães de crianças com deficiência; e b) a discussão mais geral de gênero, como forma de entender as relações entre homens e mulheres não apenas biológicas, mas também constituídas a partir de um marco cultural.

Essa discussão se justifica fundamentalmente porque, mesmo depois de todas as conquistas das mulheres após os movimentos feministas que se agudizaram na segunda metade da década de 1960, vemos enraizada socialmente uma diferenciação de papéis que se pauta na qualidade biológica das pessoas, que materializa desigualdades entre as diversas manifestações de ser masculino e feminino e que, em nosso caso específico, vem sobrecarregando mulheres que assumem/têm de assumir, como tarefa principal, o cuidado dos/as filhos/ as que apresentam deficiências e a organização da casa.

No enfrentamento a esse cenário, desde 2011, o Laboratório de Educação Física Adaptada do Centro de Educação Física e Desportos na Universidade Federal do Espírito Santo (Laefa/Cefd/Ufes) vem realizando o projeto de ensino/pesquisa/extensão denominado "Cuidadores que dançam". ${ }^{4} \mathrm{O}$ surgimento desse projeto se deu após a identificação de que as mães/pais que vinham trazer seus/suas filhos/as que apresentam deficiências para desenvolverem atividades no Laefa/Cefd/Ufes demonstravam não ter tempo para cuidar de si, visto que sua dedicação se direcionava quase exclusivamente ao/à filho/a. Como durante o tempo de atendimento de seus/suas filhos/as ficavam aguardando-os/as sem realizar nenhuma atividade, articulamos o projeto "Cuidadores que Dançam”. O projeto em tela se utiliza da linguagem dança para proporcionar um momento de descontração, convívio social e aprendizado da cultura e da historicidade a respeito das danças ao mesmo tempo que busca estimular o se (re)descobrir como pessoa, para além de ser cuidadora de filhos/ as e parentes com deficiência. 
Fonseca,Vecchi e Gama (2012) destacam a importância da dança para o desenvolvimento do sujeito, alegando que a dança proporciona o se movimentar com o outro, gerando uma maior relação com o seu corpo e com o corpo do outro, devido aos diversos sentimentos e emoções desencadeados pela dança com um parceiro. Os autores afirmam que avançar no conhecimento em dança significa se desenvolver também como pessoa.

Por outro lado, o projeto atende também ao princípo da indissociabilidade, sob o qual está vinculada a universidade brasileira: a tríade ensino/pesquisa/extensão que sustenta a formação discente. Buscamos, assim, a superação da formação puramente por acumulação de conhecimento junto aos nossos discentes, motivo que nos leva a estimular um olhar mais crítico sobre as relações sociais na formação profissional das pessoas envolvidas no projeto. Essa tríade no ensino superior deve ser integrada de forma multidisciplinar ${ }^{5} \mathrm{e}$ interdisciplinar ${ }^{6}$, a fim de articulá-las e integrá-las para um processo de ensino-aprendizagem de qualidade, capaz de compreender o sujeito em sua totalidade.

Em nosso entender, essa concepção curricular se constitui extremamente potente para os processos de formação de professores/as, favorecendo a qualificação profissional e da área, consolidando assim uma concepção de educação e, por consequência, de Educação Física, que toma a equidade de todos/as enquanto um princípio do desenvolvimento integral do/a cidadão/ã. Nesse sentido, buscar perceber as motivações sociais para que o cuidado ainda na atualidade seja atribuído fundamentalmente ao sexo feminino torna-se importante para compreender os caminhos a serem tomados para a construção da equidade de gênero.

Portanto, para efeito desse estudo, objetivamos analisar no grupo de mães participantes do projeto de ensino/pesquisa/extensão do Laefa/Cefd/Ufes "Cuidadores que dançam" o ser mulher, cuidadora de pessoas com deficiência, à luz da categoria gênero, com especial destaque para os valores e modos que percebem a realidade na qual se encontram inseridas. Ao realizar essa análise, envidamos esforços para compreender sócio-historicamente o fato de a maioria das/os cuidadoras/es ser do sexo feminino, as consequências para a vida das mulheres, a presença/ausência do pai nessa relação de cuidado e suas implicações.

\section{AproximaÇões ENTRE OS CONCEITOS DE GÊNERo E DE CUIDADO}

Nosso objeto de estudo está centrado em analisar a categoria "gênero" em relação à categoria "cuidado", o que nos estimula a refletir sobre esses conceitos. A figura de Joan Scott (1995) foi fundamental para a disseminação do conceito de gênero na academia e no movimento feminista com o texto marcante intitulado "Gênero: uma categoria útil de análise histórica", e apresenta o gênero como um saber sobre as diferenças sexuais. Gênero é concebido como uma categoria relacional, ou seja, mulheres e homens se definem em reciprocidade e a compreensão de que não pode prescindir da compreensão do outro. Finalmente, sua teoria rejeita as justificativas biológicas para a subordinação das mulheres e adota o conceito de gênero como forma de indicar o caráter das construções sociais presentes nas relações de gênero.

Pensamos que dentre as perspectivas conceituais de gênero, a trazida por Scott (1995) é fundamental para as análises aqui propostas, principalmente quando apresenta o conceito de gênero como o significado social e político historicamente atribuído ao sexo de um ser humano e capaz de evidenciar as dissimetrias e hierarquias que se expressam nas relações e práticas sociais. As relações de gênero estão presentes em todas as práticas sociais dos humanos compondo com as relações de classe e as relações étnico-raciais uma alquimia estruturante da sociedade. Assim, mesmo não sendo a única área de articulação de poder, gênero constitui-se como o principal meio em que o domínio se articula. Domínio este que repercute diretamente nas áreas de atuação de homens e mulheres, trazendo consequências relacionadas a valores, representações e hierarquias.

As discussões trazidas por Scott (1995), ainda que a partir de outra perspectiva teórica, dialogam com alguns conceitos apresentados nos estudos de Bourdieu. Para Bourdieu (2014), a dominação masculina se apresenta como uma forma particular de violência simbólica. A violência simbólica, por sua vez, seria uma forma de poder que impõe significações que se apresentam como legítimas. O poder simbólico é, dessa 
maneira, um poder invisível ou invisibilizado com a cumplicidade de quem não o percebe ou mesmo de quem o exerce. Scott (1995) também chama a atenção para a necessidade de pensar nos símbolos para superar o pensamento dualista que recai na oposição homem/mulher, masculino/feminino e que geralmente se resume em pura descrição.

Também há uma aproximação entre as ideias dos autores quando, de um lado, Bourdieu (2014) afirma que o mundo social opera a naturalização do corpo como realidade sexuada. Assim, a diferença biológica entre o corpo feminino e o masculino é usada como justificativa natural da diferença socialmente construída entre os gêneros, inclusive e, principalmente, da divisão social do trabalho. Para Scott (1995, p. 88), os conceitos de gênero "[...] estabelecidos como um conjunto de objetivo de referências" constituem uma distribuição de poder diferenciada no que tange ao controle ou acesso aos bens materiais e simbólicos. Esses conceitos são a base de estruturação de como percebemos e organizamos concreta e simbolicamente toda a vida social. Para se proteger o Poder Político, as referências devem parecer certas e fixas, "[...] fora de toda construção humana, parte da ordem natural ou divina” (p. 88) ou, como diz Bourdieu (2014), naturalizadas.

Quanto à categoria cuidado, segundo Marcondes (2013), há um decompasso no que diz respeito à equidade de gênero entre as políticas públicas para as instituições orientadas para os indivíduos e aquelas para a família. Estimulam-se políticas para a eliminação de barreiras para o acesso das mulheres à escolarização e trabalho, no entanto, pouco se faz para a promoção de políticas públicas orientadas para a desconstrução das desigualdades de gênero na família.

Legitimada historicamente como um ser delicado, carinhoso e sensível, a figura feminina vai se conformando com a pessoa apta a desenvolver tal função - cuidar. Além dessas características associadas às qualidades inatas da mulher, outro resultante dessa ideia é a divisão sexual do trabalho, na qual o homem desempenha um papel produtivo que tem forte valor social e as mulheres, o de reprodutoras, de baixo valor social (Marcondes, 2013). Essa posição reforça a figura feminina na condição de cuidadora.

Marcondes (2013) salienta que a separação social entre homens e mulheres é resultante da ideia de que o destino biológico das fêmeas é o de que cuidar é congênito e da própria escolha feminina. Baseado na ideia de que o cuidado é um destino biológico e um querer feminino e da necessidade da interação face a face para o desempenho de tal função, o homem se sentiu isento de exercer essa responsabilidade, uma vez que, por ser considerado pela mesma divisão social do trabalho como o responsável pelo papel produtivo, seria impossível que ele exercesse tal interação.

\section{Percursos metodológicos do estudo}

O estudo se configura em uma pesquisa qualitativa, com vistas a conhecer a comunidade envolvida, seus traços característicos, seus valores e modos de perceber a realidade na qual se encontra implicada (Ludke y André, 1986).

Os sujeitos do estudo foram sete mães de jovens e adultos com deficiência intelectual e autismo matriculados no Laboratório de Educação Física Adpatada da Universidade Federal do Espírito Santo (Laefa/Ufes), com idades entre 47 e 49 anos, participantes do projeto de extensão denominado "Cuidadores que dançam”. Das sete mães, três eram casadas, três viúvas e uma separada. Participavam do projeto 15 mães, porém somente sete aceitaram ser integrantes da pesquisa.

No projeto de extensão, as mães eram atendidas em um encontro semanal, todas as quintas-feiras, das $14 \mathrm{~h} 15$ às 15h45, na sala de dança do Centro de Educação Física e Desportos (Cefd/Ufes), por seis estagiários do Curso de Educação Física, sob supervisão da professora de dança e coordenadora do projeto. Essa atividade ocorria paralelamente ao atendimento das/os filhas/os nos projetos do Laefa.

Os dados foram coletados por meio de entrevista semiestruturada, contendo dez perguntas referentes à experiência de ser mãe de pessoa com deficiência na sociedade hodierna. As entrevistas foram realizadas individualmente com cada mãe, pelos autores, no mesmo dia e horário (às quintas-feiras, das 14h15 às 15h45) 
das aulas de dança, no Laefa. Houve um agendamento prévio com as entrevistadas e, no horário marcado, ocorriam as entrevistas, como segue: duas, duas e três, finalizando todas em três dias de atendimento, horário mais propício à participação delas. Todas as entrevistas foram gravadas e posteriormente transcritas de forma integral, durando em média $20 \mathrm{~min}$. Após a transcrição dos dados de entrevistas, estes foram organizados e analisados pela técnica de análise de conteúdo (Bardin, 2009), culminando na organização das seguintes categorias: a) nascimento e "morte" de um ideal de filho: sentimentos gerados e suas implicações; b) a mãe é quem cuida: o abandono por parte dos pais e o que resta para as mães.

Cabe registrar que o trabalho desenvolvido e os dados coletados foram devidamente autorizados pelas participantes ao assentirem por meio do Termo de Consentimento Livre e Esclarecido. Todas as recomendações éticas para pesquisas com seres humanos foram seguidas conforme as normas brasileiras de ética em pesquisa dispostas na Resolução no 510/2016.

\section{Nascimento E "MORTE" DE UM IDEAL DE FILHO/A: SENTIMENTOS Gerados E SUAS IMPLICAÇÕES}

Desde a gestação de uma criança, o pai e a mãe começam a sonhar com este ser que está a caminho. Idealizam a sua vida, o seu desenvolvimento, seu crescimento, independência, dentre outras expectativas. Ao saberem que este/a filho/a apresenta algum tipo de deficiência, vários desses sonhos e ideais passam a dar lugar ao sentimento de "luto" advindo da "morte" da/o filha/o idealizada/o (Amaral, 1995). Esse luto referente ao/a filho/a ideal é importante para a experiência emocional de se ter um filho/a com deficiência, visto que a deficiência carrega consigo perdas reais ou fantasiosas. Essas perdas, muitas vezes, são consequências de imaginários do próprio pai e da mãe, que pensam a deficiência por meio do tripé deficiência, incapacidade e impedimento (Amaral, 1995), desconsiderando as reais possiblidades de participação social destes indivíduos ao direcionar o olhar para a pessoa e não para os ambientes e barreiras incapacitantes produzidos socialmente. Vale salientar que este entendimento gera uma compreensão preconceituosa e discriminatórias em virtude da negação das diferenças, conforme se apresenta na fala da mãe $\mathrm{D}$ nos chama a atenção para a reação do pai ao descobrir a deficiência do filho: “[...] a mãe assume mais rápido [o cuidado do filho]. O pai, ele fica numa certa resistência, achando que o filho não vai avançar, não vai andar, não vai correr".

Tal compreensão pode desencadear o cuidado exacerbado dessa mãe, gerando a renúncia de sua vida para o cuidado do/a filho/a, a ausência de tempo para si, problemas com os/as outros/as filhos/as (se houver), problemas conjugais, abandono do trabalho e das atividades de lazer, mudança de sonhos e planos futuros. E tudo isso é fruto da mudança significativa referente a valores, atitudes e estilos de vida que são resultantes da descoberta dessa deficiência (Moura y Valério, 2003). É o que nos revela a fala da mãe D ao nos dizer sobre a relação de cuidado e de proteção com seu filho: "Nós que é mãe, assim com crianças com necessidades especiais, o filho, a gente protege muito, sabe? A gente acha que tudo vai machucar; então a gente quer, assim, tudo certinho, né?".

Além disso, sentimentos múltiplos, como o medo, a angústia, a perda e o despreparo, advêm do choque e do receio resultantes da própria notícia de conceber um/a filho/a com deficiência, como também da ansiedade de imaginar quais serão as futuras implicações dessa deficiência para a família e, principalmente, para o/a filho/ a. Esse imaginário é ainda mais aguçado dependendo da forma como a notícia lhes é dada. Isso se evidencia na fala da mãe $\mathrm{C}$ ao afirmar que, no momento em que soube da deficiência do filho, quase desmaiou: "Eu quase desmaiei porque o médico falou que ela não ia ser nada, ela ia ser um vegetal na cama, não ia andar, não ia falar, não ia enxergar, não ia ser nada”. Esse quase desmaio é resultante do susto e muitas vezes da difícil aceitação dos fatos. É causado pelo medo que, a partir daquele instante, já se faz presente, medo do desconhecido, do não planejado e esperado. Outro fator preocupante é o despreparo das/os profissionais no momento de dar a notícia. Muitas vezes a explicação sobre a deficiência é inadequada ou até mesmo inexistente (Buscaglia, 1993). 
Em nosso entender, esse cenário desvela a forte influência que o modelo médico da deficiência permeou e, ainda permeia, o olhar social em relação as pessoas com deficiência, considerando-a um ser doente, incapaz e que necessita ser curado/a para viver em sociedade. Sob esse ponto de vista, o problema centra-se na pessoa com deficiência e não na forma como a sociedade se organiza.

Com base nesse entendimento e, com a realidade da deficiência já instaurada, a mãe, que assume quase completamente o cuidado das/os filhas/os, começa a buscar por ela mesma informações e soluções para as dúvidas e dificuldades que aparecem dia após dia. A mãe $\mathrm{C}$, ao ser questionada se houve orientações e explicações acerca da deficiência por parte das/os médicos/as ou de outros/as profissionais afirma ter buscado as explicações referentes à deficiência do/a filho/a por meio de pesquisas: "[...] foi nos livros que eu vim saber o que que era. O que que eu podia tá fazendo eu fui fazendo". Essa busca que as mães e os pais têm que realizar sozinhos/as revela a ausência de políticas públicas e de espaços que possam dar suporte a essas famílias. Isso faz com que, muitas vezes, principalmente elas, se deparem com situações em que, por não saberem como agir, acabam descuidando da melhor atenção ao/a filho/a e aprendendo por ações de ensaio e erro, o que não é o mais aconselhado. Essa constatação encontra apoio em Moura e Valério (2003, p. 49) quando afirmam que:

Após o nascimento da criança deficiente, praticamente inexiste um aconselhamento psicológico aos confusos pais e grande parte do que farão com as crianças basear-se-á em ensaio e erro. Nos períodos cruciais do nascimento, quando os pais mais precisam de ajuda, esta não existe ou é muito pequena.

Conforme já discutido acima, o nascimento de um filho/a, tenha ele/a deficiencia ou não, é carregado de expectativas que nem sempre se realizam. No entanto, quando este/a filho/a vem como a "marca" da deficiencia, ele/a é a priori percebido socialmente como um ser desamparado, passivo e incapaz de assumir com autonomia a sua vida. Essa compreensão, torna-se perversamente muito mais impeditiva ao desenvolvimento desses sujeitos do que as reais limitações apresentadas por este/a filho/a ao nascer.

No enfrentanto a este cenário, espera-se que os poderes públicos assumam seu papel no âmbito da gestão de políticas comprometidas com a oferta qualitativa de projetos e programas sociais garantidores ao pleno desenvolvimento dos/as cidadãos/ãs, tenham eles/elas deficiências ou não. Entretanto, quando analisamos mais detalhadamente o cenário que perpassa as políticas destinadas a essa população, constata-se uma ausência do Estado que delega sua responsabilidade prioritariamente às instituições privadas de cunho filantrópico. Isso se evidencia ao longo das entrevistas e das conversas com as mães vem do trabalho realizado pela Associação de Pais e Amigos dos Excepcionais (Apae). É na Apae que elas são acolhidas e que recebem os atendimentos clínicos, as informações necessárias para compreender a deficiência do/a filho/a e também as orientações de como ser mãe de crianças com necessidades especiais. Essa situação pode ser ilustrada pela fala da mãe D: "Houve, sim [orientações] na Apae. Eu morava no Rio e o pessoal da Apae, os profissionais me explicou muito bem do problema do ' $T$ ”".

Além de a própria instituição trazer a essas mães as informações necessárias, ela organizava encontros quinzenais entre as famílias com o objetivo de proporcionar troca de experiências, escuta sensível, solidariedade, apoio e reconhecimento entre elas. Esse fato pode ser constatado na fala da mãe C:

[...] na Apae, quando eu comecei [a frequentar], a gente fazia reuniões com os pais de 15 em 15 dias e perguntávamos se eles tinham dificuldades, porque nós passamos por isso. Pra vê se eles tinham também. Aí, a gente pesquisava e passava pra eles o que era, porque muitos lá não tinham esclarecimento.

Essa troca de experiência e de informações não só ajuda a sanar as dúvidas que estão sempre presentes como também possibilita uma aproximação dessas mães, favorecendo a construção de amizade, de cumplicidade e de afeto.

Apesar de o Estado brasileiro já adotar uma política de inclusão das crianças com deficiência no ensino regular do sistema educacional, as mães sinalizam que ainda não veem na escola regular esse lugar de apoio à sua situação e à própria criança. As falas das mães indicam a inexistência de políticas públicas de apoio à família das pessoas com deficiência, apesar de o Estado já ter um olhar para a pessoa com deficiência de forma 
individual. Essa ausência faz com que as famílias ainda vejam na Apae, uma instituição do terceiro setor, um lugar de acolhimento. Porém, o acolhimento se dá no campo do cuidado e não de se repensar o lugar do cuidado nas relações familiares.

O projeto "cuidadores que dançam" vem problematizando essa questão junto a todos/as participantes (mães, bolsistas, voluntários/as, etc.) por entender que a questão da deficiência deva implicar toda a sociedade e, na família, implicar tanto os pais quanto as mães.

\section{A MÃE É QUEM CUIDA: O ABANDONO POR PARTE DOS PAIS}

A mulher, segundo Sigaud e Reis (1999), é legitimada pela sociedade como a única em condições ideais para atender às necessidades infantis. Sendo assim, o cuidado da/o filha/o recai sobre ela. Percebemos essa questão quando questionamos às mães sobre quem é a/o responsável na maior parte do tempo pelo cuidado das/os filhas/os, e elas reafirmam essa função social. Essa condição está presente na fala da maioria das mães, como podemos observar nos depoimentos a seguir: "[...] Eu mesmo que cuido dele desde que ele nasceu. É com ele pra tudo quanto é canto [...]” e "Sempre fui eu. Nunca ninguém cuidou dos meus filhos $[\ldots] "$.

Em alguns casos, esse cuidado é compartilhado com outros familiares, como a avó, a irmã, outra filha (quando se tem) - geralmente uma mulher. Esse cuidado a cargo, predominantemente, das mulheres tem raízes fincadas na divisão sexual do trabalho (Marcondes, 2013). Como visto, esse pensamento é consequência de uma organização social que ainda posiciona homens e mulheres em funções binárias: de produção e de reprodução, respectivamente. Nessa acepção, os homens desempenham funções de forte valor social (políticas, religiosas, militares), e as mulheres realizam as tarefas que, mesmo sendo fundamentais à sobrevivência, como a preparação da comida, a limpeza da casa e o cuidado de pessoas, são socialmente desvalorizadas.

De maneira que, quando a mulher gera filhas/os com deficiência, a responsabilidade se amplia, trazendo a essas mães um afastamento da sua vida em favor da vida da/o filha/o, como salienta a mãe A em sua fala: "É, talvez eu abri um pouco mão de coisas que eu gostaria de ter feito na minha vida. Eu abri mão, mas não me arrependo em momento nenhum". Muitas delas, nessa perspectiva, acabam interrompendo sua trajetória feminina no mercado de trabalho, como nos revela a mãe C: "Não [trabalho]. Eu comecei [a trabalhar], mas, quando eu casei, eu parei e não pude mais trabalhar". Dessa maneira, a participação no mercado de trabalho se torna ainda mais difícil após elas se casarem e terem filhas/os com deficiências.

Um fator agravante para essa situação é o abandono, direto e indireto, dos pais ao saberem da deficiência dos/as filhos/as. De acordo com Amaral (1995), os principais motivos para o abandono estão ligados: a) à não aceitação da deficiência; b) à falta de preparo do homem para o cuidado do/a filho/a (o que fortalece a ideia de que a mulher é quem foi preparada para o cuidado do filho); c) ao fato de o homem ter de trabalhar; e d) à questão relacionada com a virilidade abalada por ter tido um/a filho/a com deficiência. Essa última questão foi colocada pela mãe A, como podemos perceber em sua fala: "Isso [a deficiência] fere, no caso do homem, eu acho que a virilidade, ele ter um filho especial. Pois pensa: 'Mas eu, eu sou normal. Então, como pôde acontecer uma coisa dessas?'. Então, pra mim passa um pouco por aí".

Muitos homens não aceitam essa realidade porque idealizaram um/a filho/a saudável e fizeram vários planos que não poderão realizar pelo nascimento do/a filho/a com deficiência. Em consequência, alguns acabam abandonando a esposa e a/o filha/o para não conviver com essa realidade.

Além do abandono de forma direta, ainda ocorre o abandono indireto, que é quando muitos pais, por não saberem como agir em relação àquele quadro e também pelo cuidado ser uma atividade humana pouco designada aos homens, preferem se eximir do cuidado, deixando essa responsabilidade para as mães.

Essa atitude ocorre porque ainda existe uma ideia social muito forte, baseada na relação da divisão do cuidado explicitada por Marcondes (2013), na qual o homem tem a responsabilidade e características voltadas para a questão da produção, fazendo com que ele se sinta despreparado e isento de situações que fujam desse 
contexto, como o cuidado do/a filho/a. É evidente que essa ausência da figura paterna traz consequências para a mãe que fica sobrecarregada pelo cuidado do/a filho/a. Esse fato se evidencia na fala da mãe B: "Eu acho que haveria uma pessoa pra me ajudar um pouquinho, pra me tirar um pouquinho deles, pra poder dá mais atenção a eles, porque eles não têm, assim, afeto de ninguém. A não ser de mim mesma”.

Como percebemos na fala da mãe B, além da ajuda no cuidado do/a filho/a, a presença do pai também é muito importante para os/as filhos/as na questão afetiva. Outra implicação desse abandono paterno é a ausência de uma figura masculina, principalmente nos casos de filhos homens, que têm apenas como referência a mãe. Ao falar dessa questão, a mãe A assim se expressa: "Olha para mim. Toda família é constituída de pai, mãe e filhos. Se ela é constituída dessa forma, cada um tem o seu papel, principalmente no caso de um rapaz, um homem. Ele tem que ter um referencial masculino". Ela ainda aponta a pouca presença masculina nos locais de referência ao cuidado das pessoas com deficiência. Isso pode ser percebido na seguinte fala:

[...] a maioria das pessoas que atenderam meu filho, ao longo desse tempo, foram quase sempre mulheres. Nessas profissões eu via mais mulheres. Então, Chico, ${ }^{7}$ por exemplo, uma pessoa que acompanhou meu filho desde os quatro 4 anos de idade. Então ele via no Chicon aquela figura do homem.

Sem dúvida, a ausência da figura paterna (nessa relação em discussão) traz diversas consequências para o filho com deficiência, mas não apenas para ele, as mães também sofrem por ter que cuidar sozinhas desse/ dessa filho/a e ainda trabalhar para além dos encargos domésticos para ajudar ou, às vezes, manter totalmente o sustento da casa. É com certeza um trabalho árduo, cansativo e desgastante.

A fala da mãe se embasa numa visão binária sobre papeis referentes a homens e mulheres, dando a eles funções diferenciadas. No entanto, atualmente a organização familiar vem adquirindo novos contornos, sendo possível que uma criança seja cuidada por dois pais ou duas mães. Essa situação agrega mais um ponto de discussão sobre esse cuidado, visto que nessa família não haveria diferenciação quanto ao gênero (feminino/ masculino).

Para agravar ainda mais a situação, essas mulheres não conseguem encontrar, em meio a todas as suas "obrigações sociais", um tempo para si mesmas, um tempo para o seu lazer. Teixeira e Cerqueira (2013) sinalizam para a questão referente ao tempo fazendo um paralelo com a sua função social. Com as mudanças ocorridas a partir do modelo neoliberal, a responsabilidade que antes era assumida de maneira mais presente pelo Estado é transferida em boa parte para a sociedade, mais especificamente para as famílias que se tornam responsáveis pelo bem-estar social. Meyer (2005, p.82) destaca ainda que devido ao fato de a família ter a “[...] mulher, como mãe, no centro das políticas de gestão da vida”, esse cuidado oriundo do neoliberalismo recai mais uma vez no colo dessa mulher.

A responsabilidade social da mulher como mãe e dona de casa faz com que ela tenha que abdicar de seus sonhos e planos, antes presentes, para criar possibilidades de um futuro para o/a filho/a que agora tanto precisa de seus cuidados e atenção. Além da perda desses sonhos, a mulher perde parte da sua vida e do seu tempo "para si própria", o que gera ainda mais cansaço, stress e frustração.

Com todos os afazeres domésticos e funções maternas, perguntamos: o que resta para essas mulheres? Um tempinho? Percebemos nas falas das mães que, além da falta de tempo "em si”, existe ainda cansaço, fazendo com que elas não se sintam dispostas a fazer nem mesmo o que lhes faz bem. A mãe E afirma: "Eu não participo de nada mais ultimamente. Eu tô tão desanimada que nem indo pra igreja eu tô indo mais. Eu tô cansada, quando eu chego em casa”. Essa fala mostra que o cansaço é, na maioria das vezes, mais forte do que o desejo de fazer algo para si.

Outro fator que faz com que o tempo para o lazer seja precarizado é a preocupação em como o/a filho/a vai ficar, como será cuidado na sua ausência ou, em casos mais graves, com quem deixá-lo/a.

O momento indicado pelas mães em que podem fazer atividades voltadas para si sem se preocupar com os/as filhos/as é quando estão no projeto de extensão "Cuidadores que dançam", no Laefa/Cefd/Ufes, que 
funciona concomitantemente com o atendimentos de seus filhos/as, em atividades de esporte e lazer. Assim, enquanto os/as filhos/as estão sendo bem cuidados/as pelas/os professoras/es e estagiários/as, elas podem extravasar, se distrair e se sentir mulher por meio da dança.

A mãe A retrata bem essa realidade quando fala sobre seus sentimentos e sensações advindos desse momento voltado e pensado para elas, que é o projeto supracitado. Em seu depoimento, expressa: "Essa aula que a gente tem aqui enquanto os meninos estão fazendo as atividades deles é uma coisa maravilhosa que vocês fazem, porque a gente tem um momento de descontração".

Para essas mães, essa é uma oportunidade para que possam se distrair, sorrir, descontrair e podem, mesmo que por um curto momento de duas horas, deixar a vida de mãe em segundo plano e pensar na sua vida como mulher, para além do ser mãe e cuidadora.

\section{CONSIDERAÇÕes FINAIS}

Após nossos estudos, podemos inferir que, mesmo com todas as conquistas das mulheres quanto a uma maior participação no mundo do trabalho e também a seu maior empoderamento nas relações sociais de gênero, ainda vemos a resistência da ideia que legitima a vinculação da mulher (como essência) ao mundo reprodutivo. Essa situação é adensada em uma sociedade que ainda se desresponsabiliza pelo cuidado das pessoas e nega a atenção à saúde e educação inclusiva como um diretiro social. Isso implica que a mulher permaneça, legitimada socialmente como a principal responsável pelos afazeres domésticos e pelo cuidado dos/as filhos/as, de maneira que ela continua tendo que se organizar ou abdicar de outras funçóes sociais, como o trabalho no mundo dito produtivo, em função das atribuições do mundo dito reprodutivo.

O cuidado, no caso das mães com filhos/as com deficiência, faz com que essa renúncia como ser social livre da figura reprodutora se torne ainda mais difícil de acontecer. Influenciado por um olhar social excludente em relação às diferenças, a mãe de pessoa com deficiência vê a sua vida por meio da vida do/a filho/a, porque deixa de viver a sua vida em prol do cuidado, quase ininterrupto, dedicado ao/a filho/a.

A partir do nascimento do/a filho/a com deficiência, a mãe, em decorrência do susto e da "morte do/a filho/a idealizado/a"/(morte simbólica/luto), não pode nem viver a angústia resultante dessa descoberta, pois ela precisa quase imediatamente se posicionar para o cuidado, porque, muitas vezes, será somente dela que o/a filho/a terá o carinho, o amor e, principalmente, o "cuidado face a face". Normalmente, a mãe está tão encharcada por um olhar social da deficiência como uma condição impossibilitante que ela não se permite descobrir e olhar para esse filho para além da deficiência.

Muitas vezes esse cuidado se torna ainda mais árduo, quando a mãe se vê sozinha, sem a presença do companheiro ocasionada pelo abandono do lar ou mesmo pelo abandono de funções, uma vez que muitos pais preferem ignorar os/as filhos/as por não verem neles/as o que foi sonhado.

Além disso, outro fator que se apresentou nos estudos realizados foi a ausência de políticas públicas de base inclusiva que deem subsídios a essas mães e a seus/suas filhos/as na direção da construção de autonomia. Nessa condição, as mães acabam ficando sobrecarregas e perdendo a sua vida como ser social, passando a se constituir apenas como cuidadoras.

Por tudo que já foi dito, percebemos que as mães cuidadoras estão nesse lugar por uma construção histórico-cultural e carecem do desenvolvimento de políticas públicas comprometidas com esta questão, tanto no âmbito da garantia de equipamentos sociais para uma distribuição mais equitativa do trabalho de cuidado entre o Estado e a família, como também na promoção de políticas educacionais compromissadas com o debate ético-político atento ao reconhecimento e à valorização da diversidade (gênero, orientação sexual, étnico-racial, de gênero, sexual, religiosa, entre outros) enquanto um princípio de equidade promovedor da emancipação dos indivíduos e dos grupos sociais.

Por fim, as mães revelaram que não possuem tempo para cuidar de si, uma vez que se dedicam ao/a filho/a com deficiência, principalmente aquelas pertencentes aos estratos sociais de baixa renda. Portanto, 
cabe salientar a importância da criação de projetos voltados para os/as cuidadores/as, de preferência que aconteçam simultaneamente ao atendimento do/a filho/a com deficiência em clínicas, espaços da comunidade ou em projetos sociais similares ao do Laefa/Cefd/Ufes. Visto que tais momentos se constituem impar para que as mães/cuidadoras possam viver, pelo menos em alguns momentos, a sua própria vida, tornando-se assim uma mulher realmente desvencilhada da sua imagem como somente ser reprodutor. Ademais, a pesquisa aponta para uma necessária reconfiguração dos papéis sociais de gênero nesse processo.

\section{REFERÊNCIAS}

Amaral, L. A. (1995). Conhecendo a deficiência (em companbia de Hércules). São Paulo: Robe Editorial.

Barbosa, M. A. M., Chaud, M. N., Gomes, M. M. F. (2007). Vivências de mães com um filho deficiente: um estudo fenomenológico. Acta Paulista Enfermagem, 21(1), pp. 46-52. Recuperado de http://www.scielo.br/pdf/ape/v 21n1/pt_06.pdf

Bardin, L. (2009). Análise de conteúdo. Lisboa: Edições 70.

Blascovi-Assis, S. M. (1997). Lazer e deficiência mental. São Paulo: Papirus.

Bourdieu, P. (2005). A economia das trocas simbólicas. São Paulo: Perspectiva.

Bourdieu, P. (2014). A dominação masculina: a condição feminina e a violência simbólica. Rio de Janeiro: Bestbolso.

Brasil.Conselho Nacional de Educação. Câmara de Educação básica. (2009). Resolução nº 4, de 2 de outubro de 2009. Institui Diretrizes Operacionais para o Atendimento Educacional Especializado na Educação básica, modalidade Educação Especial. Diário Oficial da União. Brasília.

Brasil. Declaração de Salamanca e linha de ação sobre necessidades educativas especiais (1994). Brasília, Corde.

Buscaglia, L. (1993). Os deficientes e seus pais. Rio de Janeiro: Record.

Chicon, J. F.; Sá, M. G. C. S. (2012). Educação Física, adaptação e inclusão. Vitória: Universidade Federal do Espírito Santo, Núcleo de Educação Aberta e a Distância.

Falkenbach, A. P., Drexsler, G., Werler, V. (2008). A relação mãe/criança com deficiência: sentimentos e experiências, Revista Ciência e Saúde Coletiva, 13(2), 2065-2073. https://dx.doi.org/10.1590/S1413-81232008000900011

Fonseca, C. C., Vecchi, R. L., \& Gama, E. F. (2012). A influência da dança de salão na percepção corporal. Motriz: Revista de Educação Física, 18(1), 200-207. https://dx.doi.org/10.1590/S1980-65742012000100020

Ludke, M., André, E. D. A. (1986). Pesquisa em educação: abordagens qualitativas. São Paulo: EPU.

Mcnay, L. (1999). Gender, habitus and the field: Pierre Bourdieu and the limits of reflexivity. Theory, Culture \& Society, 16(1), 95-117. https://doi.org/10.1177/026327699016001007

Marcondes, M. M. (2013). O cuidado na perspectiva da divisão sexual do trabalho: contribuições para os estudos sobre a feminização do mundo do trabalho. En Yannoulas, Silvia Cristina (Ed.). Trabalhadoras: análise das profissões e ocupaçôes (pp. 251-279). Brasília: Editora Abaré.

Meyer, D. E. E. (2005). A politização contemporânea da maternidade: construindo um argumento, Revista Gênero, 6(1), 81-104.

Moura, L., Valério, N. (2003). A família da criança deficiente. Caderno de Pós-Graduação em Distúrbios do Desenvolvimento, 3(1), 47-51. Recuperado de http://www.mackenzie.br/fileadmin/Pos_Graduacao/Mestrado/ Disturbios_do_Desenvolvimento/Publicacoes/volume_III/006.pdf

Oliveira, J. F., Finelli, L. A. C. (2014). Qualidade de vida de mães com filhos atendidos na APAE de Montes Claros/ MG. Revista bionorte, 3(2), 30-38. Recuperado de http://www.revistabionorte.com.br/arquivos_up/artigos/a7 8.pdf

Pires, M. F. de C. (1998). Multidisciplinaridade, interdisciplinaridade e transdisciplinaridade no ensino. Interface Comunicação, Saúde, Educação, 2(2), 173-182. https://dx.doi.org/10.1590/S1414-32831998000100010

Scott, J. W. (1995). Gênero: uma categoria útil de análise histórica. Educação e Realidade, 20(2), 71-99. Recuperado de http://seer.ufrgs.br/index.php/educacaoerealidade/article/view/71721/40667 
Sigaud, C. H. de S., Reis, A. (1999). A representação social da mãe acerca da criança com síndrome de down. Revista da Escola de Enfermagem da USP, 33(2), 148-156. https://dx.doi.org/10.1590/S0080-62341999000200006

Silva, E. M. da. (2017). Os movimentos das professoras da educação básica do Espirito Santo em frente àspolíticas públicas de gênero para a educação (tesis doctoral).Universidade Federal do Espírito, Centro de Educação, Vitória, Espírito Santo.

Scussiatto, C. C. (2015).Inclusão: percursos e experiências educacionais no Brasil e na Itália. Informática na Educação: teoria \& prática, 18(2), 19-37. Recuperado de https://seer.ufrgs.br/InfEducTeoriaPratica/article/view/52338 136444 .

Teixeira, M., Cerqueira, M. S. (2013). O Programa Bolsa Família/Vida Melhor e as Mulheres - transferência de renda e equidade de gênero no Distrito Federal. En Yannoulas, S. C. (Ed.). Trabalhadoras: análise das profissões e ocupações (pp. 207-230). Brasília: Editora Abaré.

Venturiello, M. P. \& Ferrante, C. (2018). Discapacidad y salud desde dos investigaciones cualitativas: los itinerarios de la rehabilitación en Argentina y Chile. Apuntes, 45(83), 91-121. https://dx.doi.org/https://doi.org/10.216 78/apuntes.83.918

\section{Notas}

1 Com base na Resolução N. 4/2009, que define as Diretrizes Curriculares Nacionais Gerais para a Educação básica (BRASIL, 2009) e estabelece que a Educação Especial deve ser realizada em todos os níveis, modalidades e etapas de ensino (Art. $3^{\circ}$ ). $\mathrm{O}$ mesmo documento classifica o público-alvo da Educação Especial em: a) alunos com deficiências; b) alunos com transtornos globais do desenvolvimento; e c) alunos com altas habilidades/superdotação (Art. $4^{\circ}$ ).

2 Declaração de Salamanca (1994); Declaração Universal dos Direitos Humanos (ONU, 1948); Declaração Mundial sobre Educação para Todos (UNESCO, 1990); Declaração de Salamanca (BRASIL, 1994); Convenção da Guatemala (OEA, 1999) e; Convenção sobre os Direitos das Pessoas com Deficiência (ONU, 2006).

3 Para designar a flexão de gênero masculino/feminino, adotamos "a/o, as/os", mesmo quando falamos a partir de autores que não utilizam tal flexão, por uma opção teórico-política.

4 Projeto de extensão desenvolvido na Universidade Federal do Espírito Santo, direcionado aos acompanhantes dos 40 adolescentes, jovens e adultos com deficiência intelectual, matriculados no Laefa/Cefd/Ufes.

5 Trabalho em conjunto, o qual tenta-se articular temas comuns a serem trabalhados em disciplinas por meio da sua própria ótica (Pires, 1998).

6 Para Pires (1998) a interdisciplinaridade se apresenta como a própria superação da desarticulação da relação teoria e prática, numa relação integral na perspectiva de uma totalidade.

7 Professor de Educação Física que atua com as crianças com deficiência e teve o nome trocado para garantir o sigilo inerente a pesquisa. 